\title{
Filosofía trascendental e idealismo en Fichte
}

\section{Tom Rockmore}

Traductor: Catalina Büchner

\section{OpenEdition \\ Journals}

Edición electrónica

URL: http://journals.openedition.org/ref/555

DOI: 10.4000/ref.555

ISSN: 2258-014X

Editor

EuroPhilosophie Editions

Referencia electrónica

Tom Rockmore, «Filosofía trascendental e idealismo en Fichte », Revista de Estud(i)os sobre Fichte [En línea], 9 | 2014, Publicado el 28 diciembre 2014, consultado el 10 diciembre 2020. URL : http:// journals.openedition.org/ref/555 ; DOI : https://doi.org/10.4000/ref.555

Este documento fue generado automáticamente el 10 diciembre 2020.

(c) EuroPhilosophie 


\title{
Filosofía trascendental e idealismo en Fichte
}

\author{
Tom Rockmore
}

Tradución : Catalina Büchner

\section{NOTA DEL EDITOR}

Traducción del inglés de Catalina Büchner. Revisión de Vicente Serrano Marín. Cuando no se indique lo contrario las citas de T. R. han sido traducidas por C.B.

1 Fichte es descrito a menudo, después del Kant, como un idealista trascendental. Sin embargo, el significado de lo que se deba entender por esto sigue siendo un misterio. Kant sugiere que no interpretamos la filosofía en términos de pasajes descontextualizados, sino a través de la idea de un todo. Pero van ya más de dos siglos de falta de acuerdo acerca de lo que esto significa para Kant y tampoco está claro si existe un mayor consenso en relación a Fichte. Simplemente no sabemos qué significa "idealismo trascendental", ya que no compartimos siquiera lo que entendemos por filosofía "trascendental" ni por "idealismo".

El objetivo de este artículo es contribuir a la comprensión de la filosofía trascendental de Fichte y para ello me centraré en dos aspectos relacionados entre sí. Ni Fichte ni ningún otro filósofo es un filósofo trascendental en el completo sentido del término. Esto significa que la idea de una filosofía trascendental debería ser entendida como reguladora, pero no como constitutiva, ya que no ha sido y probablemente no será nunca completamente comprendida. Es más, creo que Fichte debería ser leído como alguien que presenta un replanteamiento radical de la filosofía crítica. Pero la filosofía crítica termina en una paradoja aparente entre dos formas de explicación cognitiva, la que se daría a partir de la diferencia entre dos explicaciones del conocimiento, diferencia que quedó en parte encubierta por la descripción que Hegel hace de Kant y Fichte como idealistas subjetivos. Me refiero, por un lado, a la explicación kantiana, que 
descansa en la interacción de sujeto y objeto, y por otro, a la fichteana, que descansa sólo en el sujeto.

\section{Hacia una interpretación de la posición de Fichte}

3 Ciertamente Fichte es un filósofo difícil de comprender. Esa dificultad se debe en parte a las características de sus textos y a su estilo complejo, pero también a la falta de entendimiento, tras de más de dos siglos de esfuerzo para alcanzar un consenso, acerca de la descripción general del idealismo y, por consiguiente, del idealismo alemán en su conjunto. Por ello mismo, existe incluso cierta confusión en el debate acerca de si es o no un idealista, (Philonenko), un romántico (Frank y Beiser) o posiblemente algo más.

En general, estos factores afectan la interpretación de todos los idealistas alemanes notables, incluidos Kant, Fichte, Schelling, Hegel y, si fuera un idealista, también Marx. El alcance del punto de vista de Fichte queda, además, enmascarado por tres factores específicos, estrechamente relacionados con ese punto de vista: primero, tenemos su consistente y a la vez confusa afirmación de que es un ferviente kantiano; segundo, existe una falta de consenso, incluso en relación a verdades básicas de la posición de Kant; y tercero, la evolución del propio Fichte. La afirmación de Fichte de ser un kantiano leal resulta una pista extremadamente importante en relación a lo que él pretende hacer en sus propios escritos. Esta afirmación se ha entendido a menudo literalmente, lo cual tiene dos consecuencias. Por una parte, oculta un logro considerable de Fichte, que no debería ser disminuido por el hecho de que se proclame discípulo de otro pensador o porque trabaje en un espacio de problemas abierto por Kant. Es obvio que Fichte pertenece a un pequeño grupo de pensadores singularmente importantes. Por un lado, la afirmación de ser un kantiano ferviente se podría refutar fácilmente al resaltar algunas diferencias básicas entre las visiones de Kant y Fichte. Sin embargo, puede ser entendida probablemente en su sentido más cabal si señalamos la importante influencia de Kant sobre el propio esfuerzo de Fichte para pensar a través de temas kantianos, y de la utilización del lenguaje y las distinciones kantianas al repensar de manera radical un modo de entendimiento de la filosofía crítica.

El segundo factor es el enigma profundo de cómo hay que entender la filosofía crítica, lo que, a su vez, determina nuestra comprensión de la filosofía trascendental de Fichte. Debido a que Fichte relaciona su posición con Kant, una adecuada comprensión de la filosofía crítica es precondición para entender la filosofía trascendental de Fichte. Y sería insuficiente a este respecto decir que, a pesar de la intensidad del debate en torno a Kant, no parecemos estar hoy más cerca de un consenso acerca del mismo que en el tiempo del idealismo alemán post-kantiano. Si hay hoy un amplio rechazo al idealismo post-kantiano es sobre todo porque hay un rechazo general del idealismo en todas sus formas. Volveré a este punto más adelante, pero es posible, de hecho probable, que Fichte, Schelling y Hegel, especialmente Fichte y Hegel, hayan sido mejores lectores de la filosofía crítica que nuestros contemporáneos. Kant, que se consideró malinterpretado, sugirió que tendemos a evitar enfoques selectivos a favor de la idea del todo; pero está claro que no existe en la actualidad ni ha existido nunca un acuerdo acerca de la filosofía crítica como totalidad.

El último factor al que hemos hecho referencia es la evolución de la posición de Fichte y la naturaleza de dicha evolución, encubierta por su hábito obsesivo de utilizar el mismo término Wissenschaftslehre en el título de las, al menos, 16 versiones de la misma. Este 
término, que evidencia la loable preocupación pedagógica de Fichte, nos sugiere la continuidad fundamental de su posición filosófica, pero también nos distrae de otras diferencias importantes. Creo que, como en el caso de cualquier otro pensador, existe una considerable continuidad en la evolución de Fichte, pero a la vez presenta diferencias muy importantes. De hecho, estas diferencias son tan relevantes que el no considerarlas socava nuestra comprensión de su obra. Fichte, que sigue a Kant en este sentido, se preocupa del conocimiento, pero, como ocurre en Kant, su comprensión del conocimiento determina a su vez una particular y original concepción acerca del sujeto. Su visión del sujeto y, por lo tanto, del conocimiento se modifica, sin embargo, como resultado de la llamada Atheismusstreit. Fichte, para quien que el tipo de filosofía que se tiene depende del tipo de persona que se es, se vio forzado por las circunstancias a ajustar sus teorías para superar, o al menos reducir, algunas dificultades inmediatas que siguieron a esa controversia. Uno de esos ajustes, por ejemplo, fue hacer depender de Dios al sujeto, lo que afectó inmediatamente la que fue, sin duda, la idea central de la Wissenschaftslehre de Jena: la afirmación de que el sujeto depende solo de sí mismo. Al discutir la posición de Fichte, me concentraré principalmente en su período temprano de Jena, tanto porque es el período de su obra que más influyó en sus escritos posteriores, como porque creo que su filosofía fue profundamente alterada y debilitó su postura a partir de la famosa Atheismusstreit.

\section{Constructivismo kantiano}

7 El espíritu de la filosofía crítica descansa sobre una idea central, la de una revolución copernicana en filosofía y, por consiguiente, depende de un enfoque constructivista del conocimiento. Este espíritu ha sido en gran medida malinterpretado en el debate general sobre el kantismo, pero fue muy bien entendido en cambio en el idealismo alemán post-kantiano. También el idealismo es en general interpretado de forma muy pobre, muy difamado y habitualmente condenado, pero raramente estudiado en detalle. El término "idealista" parece haber sido inventado por G. W. Leibniz, quien, en respuesta a Pierre Bayle, lo contrapone al sistema de "aquellos que, como Epicuro y Hobbes, creen que el alma es material". Leibniz añade, desde su punto de vista, "sea lo que haya de correcto en las hipótesis de Epicuro y Platón, de los grandes materialistas y

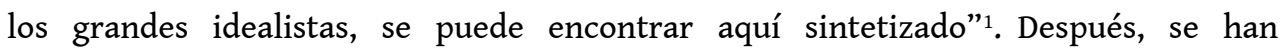
considerado a menudo como incompatibles el idealismo y el materialismo. Tanto el marxismo como la filosofía analítica anglo-americana surgen en parte de esa reacción contra el idealismo. Cuando a comienzos del siglo XX la filosofía anglo-americana emergía en Inglaterra, la crítica de Moore hacia el idealismo, en sus múltiples formas, condujo a una especie de prohibición analítica sobre el idealismo, la cual nunca ha sido abolida del todo. Más tarde, Strawson puso en circulación una influyente lectura de un Kant sin idealismo, cuya filosofía sería una forma de realismo empírico, anticipando el nacimiento de la filosofía analítica. Este realismo empírico fue considerado por algunos como una teoría de la referencia semántica.

8 Puesto que Fichte afirma ser a la vez filósofo trascendental y kantiano, es necesario entender su posición a través de la lectura que hace de la filosofía crítica. Pero no hay una única manera de leer la filosofía crítica. Kant apela a la diferencia entre el espíritu y el sentido literal al sugerir que interpretemos la filosofía crítica en términos de la idea del todo. Pero no existe ni ha existido nunca un acuerdo acerca de la filosofía crítica en 
su totalidad. Tanto en nuestros días como en tiempos de Fichte la filosofía crítica ha sido leída desde los más variados puntos de vista, y la lectura de Fichte, aunque influyente, es solo una entre muchas posibilidades. Por lo tanto, es útil distinguir entre la filosofía crítica y la lectura y el replanteamiento que Fichte hace de ella. Seguiré a Fichte y a Kant al interpretar ambas posiciones en términos de la famosa revolución copernicana. Explicar lo que cada principiante sabe o debería saber podría parecer una pérdida de tiempo, sin embargo parece necesario por la simple razón de que algunos estudiosos serios de Kant continúan negando la existencia de la revolución copernicana en la filosofía crítica o, incluso, que la filosofía crítica sea en cierto modo influenciada por Copérnico. Por el contrario, yo pienso que la revolución copernicana, término que Reinhold y Schelling utilizaban para referirse a la filosofía crítica en tiempos de Kant, es central para Kant y Fichte.

Kant, que utiliza un lenguaje representacionalista y, a veces, es entendido como un representacionalista, es de hecho un pensador profundamente antirrepresentacionalista. En esto sigue a Platón, cuyo antirepresentacionalismo está a la base de su famosa crítica de artistas y de las actividades artísticas de todo tipo. Aunque los pensadores no siempre han sido los mejores guías de su propio pensamiento, creo que en este caso no podemos hacer nada mejor que seguir a Kant para interpretar la filosofía crítica. Y a este respecto Kant nos proporciona una pista importante acerca de su postura al decirnos que él entiende a Platón mejor de lo que Platón se entendió a sí mismo.

En efecto, el acercamiento de Kant al conocimiento puede ser comprendido desde el platonismo. La teoría de las formas sugiere que podemos entender el origen de los objetos a través de su relación con las formas, las cuales no pueden ser representadas ni conocidas más que directamente a través de la intuición cognitiva. Platón rechaza la imitación (mímesis) y cualquier forma de representación y, por lo tanto, cualquier acercamiento de tipo representativo al conocimiento. Pero sí cree que existe una intuición directa, es decir, un conocimiento de la realidad. Kant, que concuerda con Platón al rechazar la representación, difiere de él al no aceptar la intuición intelectual $\mathrm{y}$, con ello, cualquier conocimiento de la realidad en sí. En lugar de esto, fundamenta el conocimiento de las apariencias en la complicada afirmación de que solo podemos conocer lo que construimos.

11 Platón niega que la representación sea un medio mejor que la intuición para conocer la realidad. Kant niega la representación al igual que intuición y, en la medida en que niega ambas, niega cualquier conocimiento de la realidad para admitir en su lugar únicamente un conocimiento completamente limitado a las apariencias. Su postura se centró en la llamada revolución copernicana, un término que jamás utiliza para identificar su posición, pero que es empleado, como he señalado más arriba, por Reinhold, Schelling y otros para referirse a la filosofía crítica mientras él vivía. Baste decir que la revolución copernicana de Kant puede ser identificada, en cualquiera de sus afirmaciones, donde una condición necesaria del conocimiento es que el sujeto debe construir, producir o de alguna manera hacer el objeto cognitivo.

Fichte entiende a Kant en términos de esa revolución copernicana, que es una teoría constructivista del conocimiento. El constructivismo, a su vez, es una teoría con raíces en las matemáticas antiguas que entra en el debate filosófico moderno a través de Hobbes y Vico y que constituye un enfoque de enorme interés, siempre y cuando se asuma que no es posible representar el objeto cognitivo. Kant descubre el 
constructivismo a partir del esfuerzo que viene realizando por formular un enfoque aceptable acerca del conocimiento, tal como lo esboza ya en su famosa carta a Markus Herz, al comienzo del llamado periodo crítico. El constructivismo kantiano está basado en una compleja interacción entre sujeto y objeto, o en la relación entre la realidad independiente de la mente, a la que llama la cosa en sí o noúmeno, y el sujeto trascendental de la apercepción o, es decir, el sujeto original de la apercepción.

La revolución copernicana de Kant se basa entonces en una inversión entre sujeto y objeto, entre el que conoce y lo que es conocido. Ofrece varias formulaciones de su principio en el prefacio B de la Crítica de la Razón Pura. En referencia a Galileo y a otros autores del siglo XVII, escribe: "comprendieron que la razón conoce sólo aquello que ella misma produce según su propio esquema". ${ }^{2} \mathrm{Y}$ en la página siguiente, después de indicar que el supuesto de que el conocimiento debe ajustarse a los objetos no ha resultado fructífero, sugiere, como experimento metafísico, "que presupongamos que los objetos tienen que ajustarse a nuestro conocimiento". ${ }^{3} \mathrm{Y}$ reformula su afirmación al inicio del crucial $\$ 14^{4}$ en la transición a la deducción trascendental de las categorías. El común denominador a través de estos y otros pasajes es la perspectiva central de la filosofía crítica, la cual sostiene que nosotros conocemos solo lo que construimos en algún sentido.

La revolución copernicana es una forma de constructivismo. Y el constructivismo se vuelve pertinente precisamente como resultado del aparente fracaso del intuicionismo $\mathrm{y}$ del representacionalismo, los otros dos principales enfoques cognoscitivos. El constructivismo se remonta al inicio de la tradición filosófica y surge, como decíamos, de las matemáticas antiguas, en particular del enfoque geométrico de la construcción de objetos, con superficie rígida y compás. Kant parece tomar como modelo del conocimiento el propio de la construcción de figuras planas. La construcción de, por ejemplo, un triángulo isósceles, prueba la existencia de la clase de triángulos isósceles. En el debate moderno, Hobbes y Vico transformaron el constructivismo matemático en un punto de vista válido para el conocimiento en general. Como tal el constructivismo ofrece una clara alternativa, basada en la consideración de que los objetos cognitivos son creados, hechos, o construidos, frente a la visión tradicional, basada en el supuesto de que el sujeto se corresponde con el objeto, que los objetos son encontrados, descubiertos o revelados.

\section{Fichte y el espíritu y la letra de la filosofía crítica}

Después de Kant, los idealistas alemanes se describieron sucesivamente a sí mismos como discípulos y seguidores de la posición de aquél, al que consideraban su maestro. Pero por ello mismo con frecuencia la filosofía de Fichte no ha sido entendida, precisamente porque su afirmación de ser un kantiano se ha interpretado como una fiel adhesión a la letra de la obra kantiana, lo que requiere una fidelidad impecable tanto al todo como a las partes. Lo cierto es que en la medida en que se dan profundas tensiones entre el espíritu y la letra en el interior de la filosofía crítica, los epígonos de Kant están obligados a elegir. En lo que a Fichte respecta, éste evita sabiamente la mera fidelidad a la letra de la filosofía crítica, esforzándose en ser leal a su espíritu. Esto explica su rechazo obvio y violento de ciertos aspectos claves de la posición de Kant, como, por ejemplo, de la cosa en sí, a la vez que proclama reiteradamente y de forma constante su ortodoxia kantiana. 
Pero la posición de Fichte puede ser entendida no sólo como un esfuerzo dirigido a llamar la atención hacia la concepción de Kant, sino también como un intento de reformular en un lenguaje diferente una visión que ha sido mal comprendida tanto en su época como en la nuestra. Este esfuerzo no tiene por qué ser polémico en sí mismo, pero lo es especialmente en la interpretación y crítica que Fichte hace de la posición de Kant, pues Fichte lleva la filosofía crítica más allá del punto en el que Kant la dejó, lo que la hace claramente discutible. Y es al interpretar la posición de Kant cuando Fichte insinúa la naturaleza de la suya propia. En ese sentido el supuesto kantismo ortodoxo de Fichte es menos un esfuerzo por llamar la atención hacia la filosofía crítica, aunque también sea eso, que un muy original esfuerzo dirigido a ofrecer una nueva formulación de la filosofía crítica y esclarecer o resolver algunas de las profundas dificultades de la filosofía de Kant. Al hacer todo eso, mediante una reformulación de esas dificultades, acaba por completar la revolución copernicana de Kant.

Pero paradójicamente es la propia filosofía crítica la que permite tal aproximación a la posición kantiana. Kant indica que todo en la teoría puede ser revisado y que un pensador original trabaja a menudo con una idea que sabe cómo utilizar pero que, igualmente, puede no entender a cabalidad. Esta visión es paradójica ya que sugiere de forma simultánea que una posición puede estar completamente desarrollada y que a la vez debe ser perfeccionada. De esta visión paradójica se siguen además otros dos aspectos. Primero, indica que aquellos que responden a un pensador original pueden superar la posición del último al refinar su premisa central. Ahora bien, muchas teorías son formuladas para responder a dificultades y problemas aún no resueltos, lo que implica que un pensador posterior pueda ser capaz de llevar la idea central de una teoría más lejos que el creador original de la misma, pues, a pesar de la pretensión de Kant, la filosofía no llegó a su punto culminante ni a su final en la filosofía crítica.

Aunque a veces Fichte da a entender que solo pretende reformular la filosofía kantiana en otros términos, para hacerla más comprensible, en realidad la somete a una crítica al rechazar aquellas doctrinas de la misma que son inconsistentes con el sentido de lo que venimos llamando giro copernicano. Incluso desvela esa intención al presentar la filosofía crítica con independencia de su autor. Así, a mediados de la década de los 90 del siglo XVIII, en un contexto filosófico extensamente dominado por Kant, Fichte escribe que su propio objetivo es la "extirpación total [de los conceptos filosóficos de la época se los llame kantianos o antikantianos] y la conversión completa del modo de pensar sobre estos aspectos de la reflexión, [...] de modo que el objeto sea puesto y determinado por la facultad cognitiva y no la facultad cognitiva por el objeto" ${ }^{5}$ Esta afirmación puede ser leída como una clara voluntad de identificar la posición de Kant a través del giro copernicano y a la vez de establecer los límites de su propia posición como una reformulación independiente en el marco de la filosofía crítica, una reformulación, que si bien no es fiel a su letra, pretende al menos ser fiel a su espíritu.

\section{Criticismo fichteano frente a constructivismo kantiano}

19 Kant distingue en el proceso cognoscitivo tres elementos explicativos: el sujeto cognoscitivo, una realidad incognoscible y el objeto del conocimiento. En la filosofía crítica el sujeto no ocupa más que un lugar epistemológico con arreglo al cual le corresponde un rol específico en la teoría cognitiva. La realidad es la causa o la fuente 
de la sensación, la cual es su pre-consciencia y, por lo tanto, como tal incognoscible. De acuerdo con el giro copernicano, el sujeto cognitivo construye el objeto cognoscible como una condición del conocimiento, condición que es necesaria pero no suficiente. Si esto es correcto, entonces podemos reconstruir y resumir la filosofía crítica a partir de Kant en un esquema como el siguiente: el sujeto cognitivo es afectado por la realidad incognoscible en la forma de la sensación, la cual, a su vez, lleva consigo un conjunto invariable y completo de categorías para la construcción de los objetos de la experiencia y del conocimiento.

El defecto del enfoque cognitivo de Kant reside en una tensión no resuelta entre el pensamiento y el ser, o entre idealismo y realismo. Esta tensión, que no puede solucionarse en la filosofía crítica, puede tal vez ser mejor reconocida si se la pone en relación con el realismo parmenideo. Kant describe su posición como idealismo trascendental y como realismo empírico y ambas formas de conocimiento apuntan a un conocimiento objetivo de lo real. Existen muchas formas diferentes de realismo: realismo metafísico, realismo artístico, realismo social, realismo empírico y así sucesivamente. El realismo de Parménides, del que se hace eco toda la tradición posterior, con frecuencia ha tomado la apariencia de un dualismo entre una forma metafísica y otra empírica, más precisamente entre un mundo externo independiente de la mente, en sentido amplio también llamado realidad, y un mundo empírico. El realismo metafísico es el término contemporáneo para referirse a las pretensiones de conocer el mundo independiente de la mente tal como éste es.

21 En el despertar de la tradición occidental, Parménides sugiere que el conocimiento requiere identidad entre pensamiento y ser. Expresado de forma más precisa, estaríamos ante una identidad que está a medio camino entre una identidad cognitiva y una no-identidad ontológica. La respuesta a la afirmación de identidad parmenidea toma dos formas principales: una afirmación de conocer la realidad como es, en la cual sabemos que es independiente de nosotros, o una afirmación de conocer solo lo que construimos en algún sentido. La primera afirmación, que es tradicional, es afirmada a menudo, pero nunca se ha propuesto un argumento para justificar tal afirmación de conocer el mundo. El enfoque constructivista alternativo ofrece una interpretación diferente de la identidad parmenídea.

Mediante el giro copernicano, Kant responde al criterio parmenídeo de que conocer es conocer la realidad o el mundo independiente de la mente y propone un enfoque basado en el sujeto cognitivo y en el mundo independiente de la mente. El enfoque kantiano, que combina aspectos constructivistas y empiristas, se asemeja en este último respecto a la teoría de la percepción causal moderna. Kant confía en la causalidad del mundo respecto al sujeto cognitivo y en la causalidad del mismo sujeto respecto de la construcción del objeto cognitivo.

23 La confianza de Kant en una teoría causal de la percepción implica tres supuestos cruciales pero indemostrables, relativos respectivamente al conocimiento de la realidad, al conocimiento de las apariencias y a la relación entre fenómeno y realidad. Respecto de lo primero, la idea central es que no podemos conocer la realidad, pero podemos construirla y, en esa medida, podemos conocer la apariencia. Kant, que afirma que no podemos conocer la realidad, afirma entonces a la vez poder conocer la existencia de la realidad. La incapacidad para conocer la realidad es el resultado de la aceptación del rechazo platónico a la inducción, central para el empirismo moderno. En otras palabras, el empirismo moderno, que niega el rechazo platónico de la inducción 
de efecto a causa, es plausible, siempre y cuando, se pueda justificar la recuperación antiplatónica de una inferencia desde los contenidos de la mente al mundo. Pero todavía no está claro si se puede afirmar, de manera consistente, no conocer la realidad pero, al mismo tiempo, conocer que ésta existe.

En segundo lugar, Kant asume la realidad del mundo externo, lo que más tarde se convierte en el tema de la llamada refutación del idealismo. El argumento de Kant consiste en afirmar que los contenidos de la conciencia son el efecto del cual es causa el mundo externo y que, por lo tanto, la realidad existe. Pero de esto sigue que existe una relación causal realidad-apariencia si y solo si la realidad aparece, lo cual aún no ha sido demostrado. Y por último, en tercer lugar, Kant asume que al conocer los fenómenos también se conoce su apariencia. Por lo tanto, la realidad aparece. Pero, aunque confía en un análisis causal, que asume y no justifica, no muestra ni puede mostrar que la realidad aparece.

\section{La filosofía trascendental de Fichte}

La posición de Fichte es una forma más profunda de constructivismo que busca contribuir al esclarecimiento de la filosofía crítica, reformulándola en un lenguaje diferente, y que, a la vez, persigue resolver las otras dificultades restantes de la versión constructivista de Kant. El constructivismo, que involucra la construcción del objeto por parte del sujeto, gira en torno a la concepción del sujeto cognitivo. Kant dice explícitamente que la unidad trascendental de la apercepción es el todo de la lógica, del entendimiento y de la filosofía trascendental.

De acuerdo con la filosofía trascendental existen objetos de experiencia y conocimiento precisamente porque existe la sensación, y que ésta a su vez se da porque existe la realidad o, para ser más precisos, porque existe una realidad independiente de la mente, que afecta al sujeto cognitivo. En otras palabras, la posición de Kant descansa sobre la realidad independiente de la mente, o la cosa en sí o, de nuevo, sobre lo que hoy es más conocido como realismo metafísico. El enfoque kantiano es inaceptable para Fichte, que rechaza el realismo metafísico como concepto explicativo.

Por ello Fichte presenta una reformulación del constructivismo kantiano que es más consistente, al despojarla de su subordinación a una realidad independiente de la mente, una reformulación que Fichte considera compatible, si no con la letra, sí al menos con el espíritu de la filosofía crítica. Al reaccionar de este modo frente a Kant define el quehacer filosófico como una explicación de la experiencia, más precisamente de los contenidos de la conciencia que van acompañados de un sentimiento de necesidad, y establece a la vez una clara distinción entre idealismo, en cuanto explicación a través del sujeto, y realismo, entendido como realismo causal. $\mathrm{O}$ para ser más precisos, una explicación a partir del efecto causado sobre el sujeto a partir de un objeto, o de una realidad, ya constituido independiente de la mente. A este respecto, formula dos objeciones dirigidas contra cualquier enfoque de explicación que dependa, parcial o totalmente, de una relación causal del conocimiento, es decir, dirigidas tanto contra la forma causal de empirismo como contra la explicación kantiana del conocimiento. En primer lugar, el realismo causal no explica lo que se supone debería explicar, pues no explica la conciencia. $Y$ en segundo lugar, el realismo causal asume pero no prueba ni deduce o justifica la existencia del mundo externo independiente de la mente. De ello se desprende que la forma kantiana de constructivismo no explique el 
efecto causal de la realidad en el sujeto y, por lo tanto, falle a la hora de explicar el conocimiento.

La posición de Kant culmina en su compleja concepción del sujeto. Fichte responde a las dificultades en la filosofía crítica al formular una concepción diferente del sujeto. La subjetividad es un tema central en la tradición moderna, pues después de Montaigne y Descartes, el camino hacia la objetividad pasa necesariamente por la subjetividad. En la medida en que no es posible regresar hacia atrás e ir más allá del sujeto moderno, tampoco es posible formular una teoría del conocimiento al margen del sujeto. El problema es entonces cómo comprender la objetividad desde la perspectiva de la subjetividad. Kant y Fichte abordan esta cuestión de maneras diferentes.

Se afirma, en ocasiones, que Fichte invierte el enfoque kantiano. Kant parte del supuesto de que existe conocimiento y a desde ahí investiga sus condiciones de posibilidad. En la filosofía crítica el sujeto es el último elemento que aparece en la deducción trascendental. Fichte invierte, sin embargo, el postulado de Kant y comienza por la concepción del sujeto en lugar de terminar con ella. En la medida en que formula su explicación de una manera radicalmente diferente, las dificultades de Fichte son muy distintas a las de Kant. Este último establece una clara distinción entre el ser humano finito y el sujeto trascendental y de este modo evita el problema que Frege y Husserl describieron más tarde como psicologismo, algo así como la sustitución del argumento psicológico por el lógico. En la filosofía crítica, la distinción entre el ser humano finito y el sujeto transcendental crea la dificultad de cómo relacionarlos ¿Está Kant analizando las condiciones generales del conocimiento? ¿O sólo del conocimiento humano finito? ¿Cómo se relacionan? Fichte, quien parte del ser humano finito, no distingue entre éste y el sujeto del conocimiento. La dificultad de Fichte no es la posibilidad y el modo de relacionar el ser humano finito y el sujeto del conocimiento, puesto que él no parte de esa distinción. Su dificultad consiste más bien en si puede justificar la objetividad del conocimiento, toda vez que él se basa exclusivamente en la subjetividad.

Esta concepción del sujeto de Fichte se entiende mejor si se la analiza sobre un doble trasfondo, el de la filosofía crítica, y el de la reacción de Reinhold, Schulze, Maimon, Kant, Schelling y otros contra Kant mismo. Reinhold fue muy importante en este contexto por su esfuerzo pionero en pretender presentar la filosofía crítica en una forma fundacionalista. Y precisamente porque Reinhold influyó en Fichte, a veces la obra de Fichte es descrita incorrectamente como un fundacionalismo cognitivo e, implícitamente, como un cartesianismo. Kant es cartesiano en algunos aspectos. El "yo pienso" (ich denke) de Kant es una traducción obvia del cogito cartesiano (je pensé) y se puede incluso defender también que esa visión del llamado "yo pienso" que debe acompañar todas las representaciones es también cartesiana. Pero Fichte no es un fundacionalista cognitivo, sino más bien un antifundacionalista cognitivo. Rechaza explícitamente el fundacionalismo al señalar que si un principio es un primer principio, no puede ser fundamentado ni definido, precisamente porque sitúa como primer principio una concepción del sujeto activo y nunca pasivo.

En el lugar de la teoría de Kant del sujeto como a la vez pasivo y activo, Fichte formula entonces una teoría del sujeto que es únicamente entendido como un sujeto activo y, por lo tanto, nunca como un sujeto pasivo. La existencia de la realidad es problemática para la filosofía crítica ya que desde una perspectiva constructivista se puede admitir solo lo que depende del sujeto. Pero esta dificultad está resuelta en la filosofía de 
Fichte, pues para él sujeto es fuente de realidad, la cual no es otra cosa que el sujeto en forma de externalidad, de alteridad. En otras palabras, para Fichte la ontología no es independiente del sujeto, sino dependiente de él.

En la Reseña de Aenesidemus, Fichte establece la base para una nueva ontología al afirmar que toda filosofía debe remontarse a un solo principio: el sujeto. Fichte observa que "[el conocimiento] más cierto e inmediato: 'Yo soy' sólo vale para el Yo [y] que todo No-Yo es sólo para el Yo". ${ }^{6}$ Su propuesta con arreglo a la cual aquello que no es el sujeto es solo para y por el sujeto da lugar a una nueva comprensión de la objetividad, desde una perspectiva de la subjetividad. Mientras que Kant reconoce dos formas de objetividad: el objeto externo independiente de la mente, o realidad, y el objeto cognitivo de la experiencia y el conocimiento, dependiente de la mente, Fichte reconoce solo una forma de objetividad: aquella que es experimentada en la práctica, pero es entendida teóricamente como resultado de la actividad del sujeto.

De acuerdo con Fichte, la tarea filosófica consiste en explicar la experiencia, a la que define como representaciones "acompañadas por el sentimiento de necesidad." Cualquier explicación de la experiencia requiere tomar en consideración su base, que es un objeto al margen de la experiencia. El análisis regresivo de Kant, que comienza con el objeto cognitivo, se extiende desde una visión de este como condicionado hasta la condición del mismo y termina en el sujeto, que es el punto más alto de la filosofía trascendental. La explicación antagónica de Fichte de la experiencia comienza no desde el objeto, sino desde el sujeto, más precisamente desde el supuesto de que "el ser racional finito no tiene nada fuera de la experiencia". 8

Según Fichte, el fundamento de toda experiencia reside fuera de la experiencia. El término "fundamento," que no se refiere al fundacionalismo epistemológico, puede ser interpretado de dos formas: bien como el objeto cognitivo que, en un marco causal, es la causa o fuente de la experiencia, o bien de nuevo como el sujeto que la experimenta. Para Fichte, un ser racional finito, o ser humano, nada puede conocer más allá de los límites de la experiencia. No podemos apuntar a conocer lo que se encuentra más allá de esos límites en la forma de un objeto ${ }^{9}$. Con esta simple afirmación, Fichte remueve la realidad, es decir, la cosa en sí kantiana, incluso como un posible objeto de investigación.

El alejamiento de la cosa en sí lleva aparejadas tres consecuencias para la concepción fichteana del conocimiento. Primero, siguiendo a Kant, abandona el realismo metafísico y lo reemplaza por el realismo empírico. El realismo metafísico, que se remonta al menos a Parménides, mantiene su popularidad. Pensadores sofisticados siguen creyendo que para conocer, debemos entender confiadamente el mundo independiente de la mente como éste es. Fichte simplemente descarta esto como algo que queda fuera de la tarea filosófica y Kant hizo hace lo mismo. Segundo, a pesar de mantener la terminología kantiana y a pesar de su atención hacia la "Deducción de la representación", Fichte abandona la representación y, con ello, abandona cualquier forma de representacionalimo. ${ }^{10}$ Para Kant, "representación" y "ap ariencia" son sinónimos. Ahora todas las apariencias son fenómenos, pero solo algunos fenómenos son apariencias. Un fenómeno es una apariencia si y solo si existe algo que aparece. En ausencia de una realidad entendida dentro de un marco causal, no existen las apariencias y, por lo tanto, no existen las representaciones. Tercero, al descartar un objeto independiente de la mente como principio explicativo, el único principio que le 
queda a Fichte, so pena de caer en el escepticismo, es apelar al sujeto o, en su propia terminología, al Yo.

El resultado, como Fichte pone de relieve inmediatamente, es un enfoque cognitivo simplificado. Desde la perspectiva de Fichte, la dificultad para la cual Kant formula la deducción trascendental no ha sido superada, pues Kant no deduce las categorías. Si esto es correcto, entonces la deducción de la representación de Fichte pretende tomar el lugar del esfuerzo anterior pero infructuoso de Kant. De acuerdo con Fichte, Kant no prueba que las representaciones posean validez objetiva, por lo tanto fracasa en demostrar su teoría. La alternativa de Fichte a la deducción trascendental de Kant presupone al menos tres puntos. Nada existe que sea más alto que el sujeto o el Yo, que funciona como su concepto explicativo último. ${ }^{11}$ Segundo, en la filosofía debemos comenzar por el sujeto, que no puede ser deducido ${ }^{12}$. Puesto que su punto de partida es el sujeto, está en contra de cualquier intento de obtener el sujeto en el contexto de la deducción trascendental. Finalmente, la deducción toma la forma de una demostración directa, genética, enfocada en el Yo. ${ }^{13}$ En resumen, al abandonar la realidad como una presuposición, abandona el objetivo kantiano de analizar la relación de las ideas en la mente hacia el mundo a favor de la "deducción" del conocimiento exclusivamente desde el punto de vista del sujeto.

La deducción de Fichte, como la de Kant, se da en una forma compleja, quasi lógica. Sin necesidad de tener que describir la deducción de Fichte en detalle, basta con decir que, partiendo de la hipótesis de que el sujeto es activo, ese mismo sujeto permanece cuando todos los demás objetos han sido ya eliminados por el poder de abstracción, y que los objetos, o el No-Yo, son precisamente aquello a partir de lo que se puede hacer abstracción. Cada uno puede ser determinado por lo otro y a la inversa. La deducción considera al sujeto desde dos perspectivas; como teóricamente infinito pero determinado en la práctica $\mathrm{y}$, con ello, finito $\mathrm{y}$, en ambos casos, como relacionado recíprocamente solo consigo mismo. Para Fichte la filosofía teórica no puede ir más lejos. Resumiendo su deducción, Fichte concluye que sujeto y objeto se determinan mutuamente el uno al otro.

\section{Fichte, filosofía trascendental e idealismo}

Fichte emerge en el ámbito del kantismo como el primer gran pensador en reaccionar a Kant. En este artículo he examinado la filosofía trascendental de Fichte a la luz de sus lecturas, y de su reformulación de la filosofía crítica. A este respecto, he centrado la atención hacia dos puntos. Primero, he insistido en que la posición de Kant es la que activa la revolución copernicana. Esto es importante, puesto que la naturaleza y rol de la revolución copernicana, que yace en el centro de la filosofía crítica, aún es objeto de controversia. Segundo, he llamado la atención hacia el rol del sujeto para ambos, Kant y Fichte. La versión de Kant del constructivismo transforma su visión del sujeto como pasivo y activo y, por lo tanto, como dependiente y no como independiente de la realidad. El rechazo de Fichte hacia la dependencia del objeto de la realidad lleva hacia su visión característica del sujeto como independiente de ella en un sentido, o como dependiente solo de sí mismo y, como resultado de ello, le lleva hacia una explicación del conocimiento única y exclusivamente a partir del sujeto.

Esta breve discusión no agota en ningún caso las dificultades relacionadas con ella. En un artículo breve como éste hay otros muchos temas implicados que no es posible 
analizar con el detalle que merecen. Pero me gustaría concluir llamando la atención sobre la paradoja que reside en el corazón de las respectivas formas de constructivismo de Fichte y de Kant y, por lo tanto, aunque no puedo argumentar ahora por extenso este punto, en el centro del idealismo alemán. En un sentido, sus enfoques son complementarios. Kant sugiere una relación entre el sujeto y una realidad independiente de la mente, imposible de conocer, para explicar el conocimiento objetivo. Frente a ese análisis de Kant, Fichte propone que la experiencia y el conocimiento pueden ser entendidos meramente a través del sujeto, sin ninguna concepción de la realidad independiente de la mente. El constructivismo kantiano es insuficiente al depender de una realidad que no puede explicar. Aunque la forma de constructivismo revisado de Fichte probablemente también es insuficiente, pues no parece posible explicar el conocimiento objetivo únicamente mediante una concepción del sujeto, es decir, sin una visión suficientemente fuerte de la limitación empírica. Concluyo, pues, señalando que, si bien ambos contribuyen de manera notable a un enfoque constructivista del conocimiento, ninguno de ellos formula una versión satisfactoria del constructivismo. $Y$ aunque Fichte reacciona antes las insuficiencias del constructivismo kantiano, y va más lejos que él, tampoco alcanza a encontrar esa versión satisfactoria del constructivismo.

\section{Bibliografía}

FICHTE, J. G., Early Philosophical Writings, edited and translated by Daniel Breazeale, Ithaca: Cornell University Press, 1988.

FICHTE, J. G., Science of Knowledge, with First and Second Introductions, edited and translated by Peter Heath and John Lachs, New York: Cambridge University Press, 1982.

KANT, I., Critique of Pure Reason, translated by Paul Guyer y Allen Wood, Nueva York: Cambridge University Press, 1998.

LEIBNIZ, G. W., Philosophische Schriften, GERHARDT, C. I. (Ed.), Berlin: Weidmann, 1875-1890.

THOMAS-FOGIEL, I., Critique de la representation. Etude sur Fichte, París: Vrin, 2000.

\section{NOTAS}

1. LEIBNIZ, G. W., Philosophische Schriften, GERHARDT, C. I. (Ed.), Berlin: Weidmann, 1875-1890, IV, 559-560.

2. KrV B XIII.

3. KrV B XVI.

4. $\mathrm{KrV}$ B 125.

5. EE, GA I/4, 184. Trad. de Emiliano Acosta.

6. ResAe, GA I/2, 62. Trad. E. A.

7. EE, GA I/4, 186. Trad. E. A.

8. EE, GA I/4, 188. Trad. E. A. 
9. EE, GA I/4, 188-189.

10. Cf. THOMAS-FOGIEL, I., Critique de la représentation. Etude sur Fichte, París: Vrin, 2000.

11. GWL, GA I/2, 390-391.

12. GWL, GA I/2, 388-389.

13. GWL, GA I/2, 395-396 y 434.

\section{RESÚMENES}

The aim of this paper is to contribute to a grasp of Fichte's transcendental philosophy. In this respect, I will be making two related points. Neither Fichte nor anyone else is a transcendental philosopher in the full sense of the term. This means that the very idea of transcendental philosophy should be understood regulatively but not constitutively since it has not and probably cannot be fully realized. Further Fichte should be read as presenting a radical restatement of the critical philosophy that ends in an apparent paradox between two modes of cognitive explanation, whose difference is masked through Hegel's description of both Kant and Fichte as subjective idealists: in short either explanation through the interaction of both subject and object, or again through the subject only.

\section{ÍNDICE}

Keywords: constructivism, critical philosophy, transcendental idealism, subjectivism, Copernican turn

\section{AUTORES}

\section{TOM ROCKMORE}

Universidad Duquesne - Universidad de Pekín 